Journal of Back and

Musculoskeletal Rehabilitation

\title{
Calendar \\ Lumbar Segmental Instability Fact or Fiction?
}

\author{
November 21-22, 1997, \\ International Symposium, Brussels, Belgium \\ Controversies in diagnosis, management and costs
}

The faculty includes A. Nachemson, A.A. White, G. Waddell, H.V. Crock, M. Adams, M. Pope, R. Mulholland, B. Rydevik, C. Galasko, R. Porter. P. Van Akkerveeken, D. Chopin, M. Nordin, J.-L. Dietemann, P. Parizel, M. Benoist, K. Burton, A. Gardner, C. Ray, A. Rogozinski, M. Mayer, P. Lapresle, C. Mélot, M. Sullivan, F. Balagué,

C. Greenough.

\author{
Contact: R. Gunzburg, M.D., Ph.D \\ Brugmann University Hospital \\ Dept of Orthopaedics \\ 4, Place van Gehuchten \\ 1020 Brussels \\ Belgium \\ Fax: $32 / 2 / 4780091$ \\ $32 / 3 / 2402040$ \\ Eurospine 2000
}

October 9-13, 2000,

Antwerp, Belgium

Annual meeting of the European Spine Society \& European Spinal Deformity Society

Contact: R. Gunzburg, M.D., Ph.D.

Niellonstr. 14,

2600 Berchem

Belgium

Fax: 32/3/240 2040

$32 / 3 / 2187841$

1053-8127/97/ $\$ 17.00$ C 1997 Elsevier Science Ireland Ltd. All rights reserved. PII S1053-8127(96)00253-0 